\title{
The Pre-Symbiotic Growth of Arbuscular Mycorrhizal Fungi Is Induced by a Branching Factor Partially Purified from Plant Root Exudates
}

\author{
M. Buee, ${ }^{1}$ M. Rossignol, ${ }^{1}$ A. Jauneau, ${ }^{2}$ R. Ranjeva, ${ }^{1}$ and G. Bécard ${ }^{1}$ \\ ${ }^{1}$ Signaux et Messages Cellulaires chez les Végétaux, UMR 5546 CNRS/Université P. Sabatier, Pôle de \\ Biotechnologie Végétale, 24 chemin de Borde Rouge, BP 17 Auzeville, Castanet-Tolosan, France; \\ ${ }^{2}$ Institut Fédératif de Recherche F.R. 40, CNRS, Pôle de Biotechnologie Végétale, BP 17, Castanet- \\ Tolosan, France \\ Accepted 7 March 2000.
}

\begin{abstract}
Arbuscular mycorrhizal (AM) symbiosis is an association between obligate biotrophic fungi and more than $80 \%$ of land plants. During the pre-symbiotic phase, the host plant releases critical metabolites necessary to trigger fungal growth and root colonization. We describe the isolation of a semipurified fraction from exudates of carrot hairy roots, highly active on germinating spores of Gigaspora gigantea, G. rosea, and G. margarita. This fraction, isolated on the basis of its activity on hyphal branching, contains a root factor (one or several molecules) that stimulates, directly or indirectly, $G$. gigantea nuclear division. We demonstrate the presence of this active factor in root exudates of all mycotrophic plant species tested (eight species) but not in those of nonhost plant species (four species). We negatively tested the hypothesis that it was a flavonoid or a compound synthesized via the flavonoid pathway. We propose that this root factor, yet to be chemically characterized, is a key plant signal for the development of AM fungi.
\end{abstract}

Arbuscular mycorrhizal (AM) symbiosis is a very ancient plant-microbe association between some Zygomycete (order Glomales) fungi and more than $80 \%$ of land plants (Smith and Read 1997). AM fungi contribute to plant health as they improve plant nutrition and, in most instances, plant resistance against pathogen attacks (St.-Arnaud et al. 1995; GianinazziPearson et al. 1996). In turn, the host plant supplies carbon to the fungal partner, an obligate biotroph incapable of accomplishing its life cycle in the absence of a host plant. In spite of this obligate biotrophism, spores of AM fungi are generally capable of spontaneous germination as long as some physical and physiological conditions are fulfilled. Germ tube growth occurs for 1 to 3 weeks (depending on the species of fungus) but ceases long before consumption of spore reserves if a host root is not present in the environment (Bécard and Piché 1989b). Several authors have described growth stimulation of germinating AM fungi in the presence of host root exudates

Corresponding author: Guillaume Bécard; E-mail: becard@cict.fr
(Mosse and Hepper 1975; Graham 1982; Elias and Safir 1987; Bécard and Piché 1989a, 1989b; Giovannetti et al. 1993; Tawaraya et al. 1996), while exudates from nonmycotrophic species had no effect (Gianinazzi-Pearson et al. 1989; Bécard and Piché 1990; Giovannetti et al. 1994; Giovannetti and Sbrana 1998) or appeared to be inhibitory (Koide and Schreiner 1992; Vierheilig and Piché 1995). Therefore, it is conceivable that host plants release critical metabolites needed to trigger a further step in fungal growth and development. This step would be a prerequisite for the fungus to exploit its reserves entirely and to succeed in host root colonization. Signals derived from growing roots of Ocimum basilicum, eliciting branching of Glomus mosseae, were hypothesized by Giovannetti et al. (1996). The active product(s) were not isolated and their chemical structure is yet to be determined.

We have isolated a semipurified fraction from exudates of hairy roots of Daucus carota L. that is highly active on germinating spores of Gigaspora gigantea (from an agricultural field in Kutztown, PA). This fraction, isolated on the basis of its activity on hyphal branching (see below), contains a root factor (one or several molecules) that we will call the "branching factor." Hairy roots of D. carota were propagated on a minimal (M) medium (Bécard and Fortin 1988) in petri dishes at $28^{\circ} \mathrm{C}$ for 3 weeks. They were aseptically transferred to sterile, distilled water (approximately $500 \mathrm{mg}$ of equivalent root dry weight per $100 \mathrm{ml}$ of water) and left to soak for 2 days at $25^{\circ} \mathrm{C}$ in the dark. They were oxygenated with sterile air with an aquarium pump. Crude root exudates were filtered $(0.2 \mu \mathrm{m})$ before purification and the filtrate caused hyphal branching when tested directly on germinating spores. The filtrate was fractionated and the fractions to be tested were concentrated to $2 \mu \mathrm{l}$ per $1 \mathrm{mg}$ of equivalent root dry weight. This concentration served as a reference to compare the activities of the various fractions within one plant species, and the fractions of different species with each other. The first step in the purification of the root exudates involved a phase separation (ethyl acetate/aqueous) of root exudates where all the activity remained in the ethyl acetate. This fraction was dried under vacuum and resuspended in methanol, and an inactive insoluble fraction was removed by centrifugation. The super- 
natant was then dried under vacuum, resuspended in ethyl acetate/hexane (1/4), and centrifuged. The activity remained in the supernatant. Essentially, the purification procedure eliminated macromolecules, water-soluble molecules, and the most hydrophilic compounds soluble in the ethyl acetate.

Activity of root exudates was tested according to a bioassay (Fig. 1) developed on G. gigantea by Nagahashi and Douds (1999). Three to five surface-sterilized spores of G. gigantea were placed inside a gel ( $20 \mathrm{ml}$ of solidified $0.4 \%$ Phytagel, M medium) in 80-mm-square, plastic petri dishes (Bécard and Fortin 1988). By incubating $\left(2 \% \mathrm{CO}_{2}, 32^{\circ} \mathrm{C}\right)$ the dishes vertically, the negative geotropism of $G$. gigantea germ tubes was exploited to direct hyphal growth upward. The germinated spores were allowed to grow 4 to 6 days before the addition of the exudates. Sterile Pasteur pipettes were used to make two small wells ( $2 \mathrm{~mm}$ in diameter) by suction in the gelled medium, one on each side of the tip of the growing germ tubes. Five microliters (exudates produced by $2.5 \mathrm{mg}$ of equivalent root dry weight) of the different root exudate fractions, dissolved in water/methanol (1:1), was injected into each well. Injections of water/methanol (1:1) were used for controls. Only one germinating spore per dish was stimulated. The two to four neighboring germinating spores were subjected only to diffusing fractions. The intensity and the delay of their response (18 $\mathrm{h}$ after injection) provided additional information that we used to make a semiquantitative interpretation of fraction activity. The fungal response was observed $18 \mathrm{~h}$ after stimulation and characterized by the formation of new hyphal branches along the germ tube. Control hyphae appeared straight with few lateral branches (Fig. 1A) whereas the treated hyphae showed different patterns of hyphal branching, depending on the proximity of branching factor injection. Near the stimulation area (less than $20 \mathrm{~mm}$ ), hyphal branching was very intense, with the formation of many clusters of short and curled hyphae (Fig. 1B). Beyond $30 \mathrm{~mm}$ from the injection zone, the branching pattern was less twisted and curled (Fig. 1C), showing fewer but longer branches. The first branches appeared between 5 and $8 \mathrm{~h}$ after the addition of the branching factor. For the experiments of growth quantification and nuclear staining (see below), five injections were made in the gelled medium (four at the corner and one in the middle) just prior to spore inoculation.

Four days after germination in the presence of the branching factor, the total hyphal length of the stimulated fungi was threefold greater than the total hyphal length of controls (Fig. 2). After 10 days of growth, two methods of quantification, including image processing, showed that the treatment caused an approximately 4.5-fold increase in total hyphal length (Fig. 2 and Table 1). This hyphal growth stimulation was characterized by the formation of new primary branches (Table 1), each exhibiting intense branching activity. For example, 5 days after stimulation the mean number $(n=5)$ of hyphal apices per germinating spore was $205 \pm 17$ ( \pm SEM) in the presence of the branching factor and $7 \pm 1$ ( \pm SEM) for the control. In contrast, the elongation of the germ tubes and the number of auxiliary cells were not significantly different between the control and the treatment (Table 1).

To correlate the proliferation of hyphal branches with cell growth stimulation, the nuclear status of G. gigantea was examined 5 days after spore germination in the presence or absence of branching factor. Growing hyphae were fixed in the culture dishes with $70 \%$ ethanol for $1 \mathrm{~h}$ then rinsed several times with deionized water. The dishes were dried in an oven at $60^{\circ} \mathrm{C}$ for $3 \mathrm{~h}$ to obtain a very thin-layer of gel. Nuclei were stained with 4' 6-diamidino-2-phenylindol (DAPI; Sigma, St. Louis, MO) dissolved in liquid $\mathrm{M}$ medium to a final concentration of $5 \mu \mathrm{M}$. After $12 \mathrm{~h}$ of staining in the dark at $4^{\circ} \mathrm{C}$, samples were rinsed and the number of nuclei were counted under UV light with an inverted fluorescence microscope. For each condition ( \pm exudates) the nuclear density was calculated in hyphae of five germinating spores after random sampling of 50 hyphal segments (10 segments of 150 to $200 \mu \mathrm{m}$ per germinating spore). Prior to counting the nuclei, microscopic images were acquired with an inverted Leica DMIRBE microscope equipped with epifluorescence illumination $(100 \mathrm{~W}$ mercury lamp, dichroic mirror $400 \mathrm{~nm}$, excitation 340 to 370 $\mathrm{nm}$, barrier $430 \mathrm{~nm}$ ) and a color cool view device camera (Photonic Science, Robertsbridge, U.K.). The number of nuclei per millimeter of hyphae remained constant, between 101 $\pm 6( \pm$ SEM $)$ and $113 \pm 5( \pm$ SEM $)$ in control and treated hyphae, respectively, but the total number of nuclei was threefold higher for the treated fungi. The staining intensity of the nuclei was also consistently stronger in the branching structures and at the hyphal tips. To exclude the possibility that the more numerous nuclei we observed were of spore origin, i.e., existed before the branching factor was added, we removed the spores before adding the branching factor and observed the severed germ tubes after $15 \mathrm{~h}$. They exhibited the same branching response as hyphae still attached to their spores. The number of nuclei per millimeter of hyphal length was the same in control and treated germ tubes: $128 \pm 2( \pm$ SEM) and $130 \pm 6( \pm$ SEM $)$, respectively. Therefore, the treated hyphae contained a proportionally larger number of nuclei. Hyphal branching in filamentous fungi is physiologically equivalent to cell proliferation for unicellular organisms like yeast. Every new hyphal tip is like a new life unit where most of the cell machinery is located. When a fungus is under stress, branching is also a common response. Several of our data support the cell proliferation hypothesis rather than the hypothesis of a stress response. New apices, which appeared $5 \mathrm{~h}$ after the addition of the root factor, emerged laterally while the tip of the main hypha was still actively growing. The overall hyphal length increased considerably and, more importantly, the number of nuclei increased proportionally. Nuclear division gives a good indication of active growth for a filamentous fungus, particularly when it is coenocytic. It will be important to determine whether the branching factor affects the fungal cell cycle directly, or if the rise in the number of nuclei is simply a consequence of hyphal branching.

Two more species of AM fungi, Gigaspora margarita (BEG34, purchased from Biorhize, Dijon, France) and Gigaspora rosea (DAOM 194757, maintained in pot culture with leek) were treated with the branching factor purified from the D. carota hairy roots as previously described for G. gigantea. The two Gigaspora species responded by strong hyphal branching in the same way as $G$. gigantea. The growth stimulation of $G$. margarita was particularly intense, although this fungus showed a slightly delayed response ( $24 \mathrm{~h}$ ). Moreover, G. margarita seemed to exhibit enhanced longevity.

We also tested whether the branching factor present in exudates of carrot hairy roots was present in root exudates of a wide variety of plant species. Twelve species that belong to 


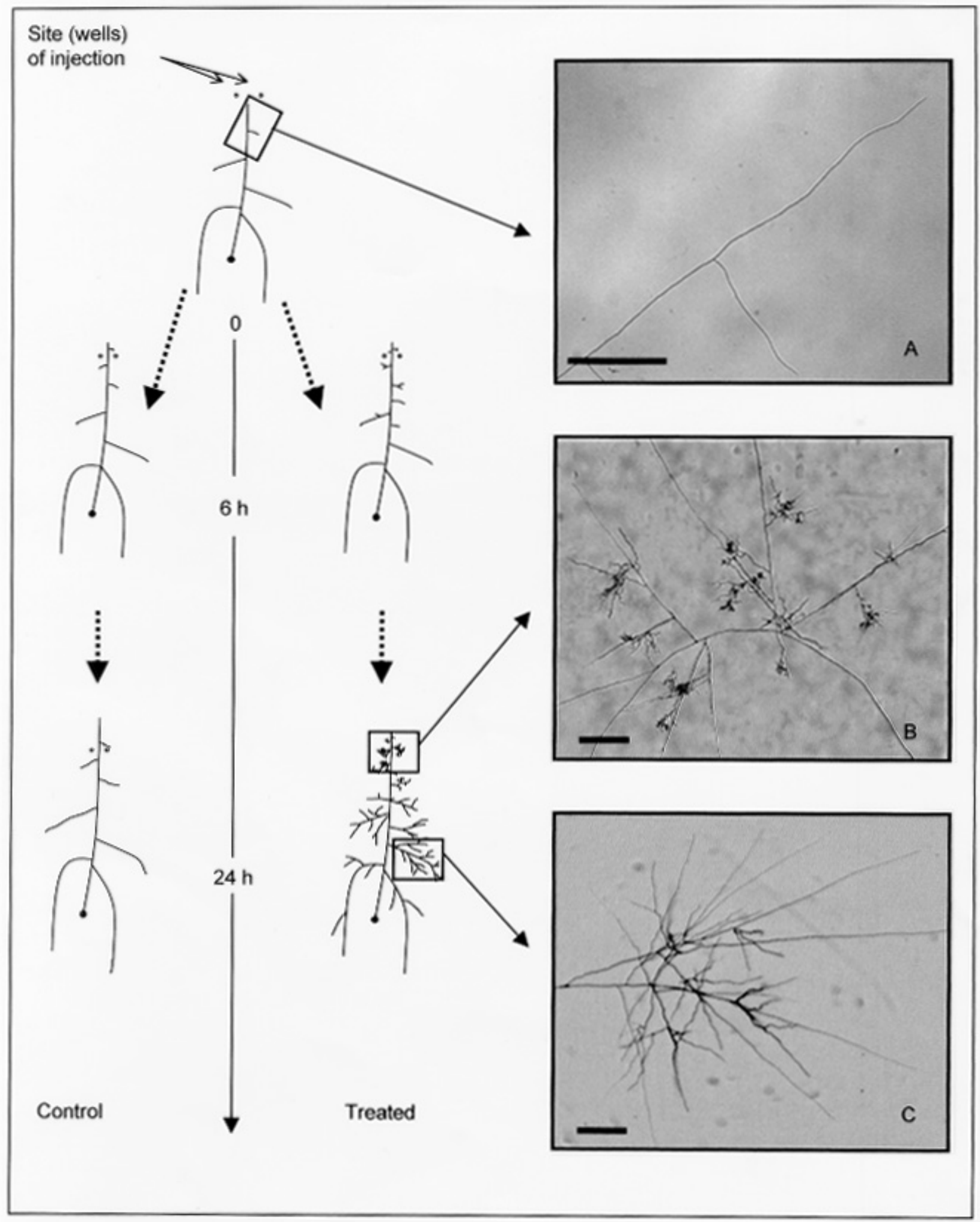

Fig. 1. In vitro experimental system showing stimulation of growth and branching in a Gigaspora gigantea germ tube after microinjection (5 $\mu$ l per well) of root exudates, and microscopy images showing different growth and branching patterns of G. gigantea in the presence of branching factor. A, Nontreated hypha. B, Treated hypha: strong branching with an important number of arborescent structures (arrows). C, Fungal branching observed in a distant area of the branching factor injection. Scale bars $=200 \mu \mathrm{m}$. 
(1993) reported that $G$. mosseae hyphae were chemoattracted to the root. We did not observe such chemotropism with $G$. gigantea hyphae either in the presence of a growing root or in the presence of the branching factor. These differences were observed with two different fungi. They can also be explained by the two experimental systems used.

Since a number of authors have shown that some flavonoids stimulate the growth of AM fungi (Gianinazzi-Pearson et al. 1989, Tsai and Phillips 1991; Bécard et al. 1992; Chabot et al. 1992; Fries et al. 1997; Vierheilig et al. 1998), these plant chemicals have often been presented as fundamental signals in plant-fungus communication during the pre-infection stages of endomycorrhizal symbiosis (Hirsch and Kapulnik 1998; Vierheilig et al. 1998). The well-established importance of flavonoids as signals in other plant-microbe interactions (Long 1989; Shirley 1996), the observation that these metabolites stimulate growth of AM fungi in vitro, and the fact that plant roots contain flavonoids are not sufficient arguments that naturally occurring flavonoids are necessary plant signals in endomycorrhizal symbiosis. Significant amounts of quercetin, myricetin, and kaempferol, flavonoids with strong stimulatory activity on some AM fungi, have been detected in nonmycorrhizal plants such as Arabidopsis thaliana (Burbulis et al. 1996). The only study that attempted to demonstrate this natural occurrence had to conclude that flavonoids were not necessary plant signals for AM symbiosis (Bécard et al. 1995). Maize mutants deficient in the biosynthesis of flavonoids were colonized by several AM fungi, as well as the wild type. These data suggested that other plant molecules, yet to be discovered, are responsible for the fungal growth stimulation and could be the plant signals needed to trigger a developmental stage in AM fungi that precedes successful root colonization. In the present study, we used the same chalcone synthasedeficient mutants of maize to determine whether the branching factor was synthesized via the flavonoid pathway. We found no difference in the capacity of mutant and wild-type maize to produce stimulatory exudates, strongly suggesting that the branching factor does not include flavonoids.

By taking advantage of the sensitivity and the strength of the fungal branching bioassay, a series of chemicals known to have biological activity in plant-microbe interactions were directly tested on G. gigantea (Table 3). For each chemical, we tested different concentrations based on the literature and we assayed the fungal response 18 to $96 \mathrm{~h}$ after injection into the medium near the hyphal tip. None of the chemicals caused fungal branching nor did they have any inhibitory effect, ex-

Table 3. Chemicals ${ }^{\mathrm{a}}$ with no branching activity on hyphae of germinating spores of Gigaspora gigantea

\begin{tabular}{|c|c|c|}
\hline Compound & Concentration & References \\
\hline Abietic acid & 1,10, and $100 \mu \mathrm{M}$ & Fries et al. 1987 \\
\hline Bra & 1,10 , and $100 \mathrm{nM}$ & Yok \\
\hline $17 \beta$-estradiol & 10 and $100 \mathrm{nM}$ & Poulin et al. 1997 \\
\hline Jasmonic acid & 5 and $10 \mu \mathrm{M}$ & Regvar et al. 1996 \\
\hline Nod factors ${ }^{\mathrm{b}}$ & $10 \mathrm{nM}, 100 \mathrm{nM}$, and $1 \mu \mathrm{M}$ & Xie et al. 1995 \\
\hline Quercetin & 1,10 , and $100 \mu \mathrm{M}$ & Bécard et al. 1992 \\
\hline Salicylic acid & $100 \mathrm{nM}$ and $50 \mu \mathrm{M}$ & Rhodes 1994 \\
\hline \multicolumn{3}{|c|}{$\begin{array}{l}\text { a Phenolic compounds were obtained from Sigma Chemical (St. Louis, } \\
\text { MO). Nod factors were kindly provided by D. Barker (UMR } 215 \\
\text { CNRS/INRA, Castanet-Tolosan, France) and brassinolide was obtained } \\
\text { from CIDtech (Mississauga, Ontario, Canada). }\end{array}$} \\
\hline
\end{tabular}

cept $50 \mu \mathrm{M}$ salicylic acid, which had an inhibitory effect on hyphal growth. This suggests that these chemicals are not natural hyphal branching factors or that the concentrations tested were not able to trigger a biological response. The chemical identification of the branching factor will determine whether it corresponds to already described plant metabolites or not.

Growth stimulation and hyphal branching of AM fungi in the vicinity of a host root have long been described as one of the first events in host root recognition by the fungus during the pre-symbiotic phase (Mosse and Hepper 1975; Powell 1976; Bécard and Piché 1989a; Giovannetti et al. 1993, 1994, 1996). A number of studies have attempted to characterize the exuded root compound(s) responsible for stimulation of growth and branching (Nair et al. 1991; Bel Rhlid et al. 1993) but none have tried to isolate the active molecules from crude material. For the first time, we isolated a semipurified root extract (branching factor) that can mimic the presence of a host root by triggering a typical pre-symbiotic fungal response within a few hours. At this stage of our knowledge, we propose that plant root exudates contain some lipophilic compound(s) that we call branching factor, yet to be chemically characterized, with an activity (direct or indirect) on cell proliferation of AM fungi. We hypothesize that this branching factor is a plant signal needed to trigger the developmental stage of the fungus that precedes successful root colonization.

\section{ACKNOWLEDGMENTS}

We thank Natacha Bourgarel for her technical assistance and Valeria Bianciotto and Sonja Kosuta for critical reading of the manuscript. We also thank L. Taylor and V. Gianinazzi-Pearson for providing seeds of $\mathrm{CHS}^{-}$maize and $\mathrm{Myc}^{-}$pea, respectively. This research was supported by the Ministère de l'Éducation Nationale, de la Recherche et de la Technologie (MENRT), and by the company Premier Tech (Rivière-du-loup, Québec, Canada).

\section{LITERATURE CITED}

Bécard, G., Douds, D., and Pfeffer, P. 1992. Extensive in vitro hyphal growth of vesicular-arbuscular mycorrhizal fungi in the presence of $\mathrm{CO}_{2}$ and flavonols. Appl. Environ. Microbiol. 58:821-825.

Bécard, G., and Fortin, J. A. 1988. Early events of vesicular-arbuscular mycorrhiza formation on Ri T-DNA transformed roots. New Phytol. 108:211-218.

Bécard, G., and Piché, Y. 1989a. Fungal growth stimulation by $\mathrm{CO}_{2}$ and root exudates in vesicular-arbuscular mycorrhizal symbiosis. Appl. Environ. Microbiol. 55: 2320-2325.

Bécard, G., and Piché, Y. 1989b. New aspects on the acquisition of biotrophic status by a vesicular-arbuscular mycorrhizal fungus, Gigaspora margarita. New Phytol. 112:77-83.

Bécard, G., and Piché, Y. 1990. Physiological factors determining vesicular-arbuscular mycorrhizal formation in host and non-host Ri TDNA transformed roots. Can. J. Bot. 68:1260-1264.

Bécard, G., Taylor, L. P., Douds, D. D., Jr., Pfeffer, P. E., and Doner, L. W. 1995. Flavonoids are not necessary plant signal compounds in arbuscular mycorrhizal symbioses. Mol. Plant-Microbe Interact. 8:252258.

Bel-Rhlid, R., Chabot, S., Piché, Y., and Chênevert, R. 1993. Isolation and identification of flavonoids from Ri T-DNA transformed roots (Daucus carota) and their significance in vesicular-arbuscular mycorrhiza. Phytochemistry 33:1369-1371.

Burbulis, I. E., Iacobucci, M., and Shirley, B. W. 1996. A null mutation in the first enzyme of flavonoid biosynthesis does not affect male fertility in Arabidopsis. Plant Cell 8:1013-1025.

Carr, G. R., Hinkley, M. A., Le Tacon, F., Hepper, C. M., Jones, M. G. K., and Thomas, E. 1985. Improved hyphal growth of two species of 
vesicular-arbuscular mycorrhizal fungi in the presence of suspensioncultured plant cells. New Phytol. 101:417-426.

Chabot, S., Bel-Rhlid, R., Chênevert, R., and Piché, Y. 1992. Hyphal growth promotion in vitro of the VA mycorrhizal fungus, Gigaspora margarita Becker \& Hall, by the activity of structurally specific flavonoids compounds under $\mathrm{CO}_{2}$-enriched conditions. New Phytol. 122:461-467.

Duc, G., Trouvelot, A., Gianinazzi-Pearson, V., and Gianinazzi, S. 1989. First report of non-mycorrhizal plant mutants $\left(\mathrm{Myc}^{-}\right)$obtained in pea (Pisum sativum L.) and fava bean (Vicia faba L.). Plant Sci. 60:215222.

Elias, K. S., and Safir, G. R. 1987. Hyphal elongation of Glomus fasciculatus in response to root exudates. Appl. Environ. Microbiol. 53: 1928-1933.

Fries, L. L., Pacovsky, R. S., Safir, G. R., and Siqueira, J. O. 1997. Plant growth and arbuscular mycorrhizal fungal colonization affected by exogenously applied phenolic compounds. J. Chem. Ecol. 23:17551767.

Fries, N., Serck-Hanssen, K., Dimberg, L., and Theander, O. 1987. Abietic acid, an activator of basidiospore germination in ectomycorrhizal species of the genus Suillus (Boletaceae). Exp. Mycol. 11:360-363.

Gianinazzi-Pearson, V. 1996. Plant cell responses to arbuscular mycorrhizal fungi: Getting to the roots of the symbiosis. Plant Cell 8: 1871-1883.

Gianinazzi-Pearson, V., Branzanti, B., and Gianinazzi, S. 1989. In vitro enhancement of spore germination and early hyphal growth of a vesicular-arbuscular mycorrhizal fungus by host root exudates and plant flavonoids. Symbiosis 7:243-255.

Gianinazzi-Pearson, V., Dumas-Gaudot, E., Gollotte, A., Tahiri-Alaoui, A., and Gianinazzi, S. 1996. Cellular and molecular defence-related root responses to invasion by arbuscular mycorrhizal fungi. New Phytol. 133:45-57.

Giovannetti, M., and Sbrana, C. 1998. Meeting a non-host: The behaviour of AM fungi. Mycorrhiza 8:123-130.

Giovannetti, M., Sbrana, C., Avio, L., Citernesi, A. S., and Logi, C. 1993. Differential hyphal morphogenesis in arbuscular mycorrhizal fungi during pre-infection stages. New Phytol. 125:587-593.

Giovannetti, M., Sbrana, C., Citernesi, A. S., and Avio, L. 1996. Analysis of factors involved in fungal recognition responses to host-derived signals by arbuscular mycorrhizal fungi. New Phytol. 133:65-71.

Giovannetti, M., Sbrana, C., and Logi, C. 1994. Early processes involved in host recognition by arbuscular mycorrhizal fungi. New Phytol. 127:703-709.

Glenn, M. G., Chew, F. S., and Williams, P. H. 1988. Influence of glycosinolate content of Brassica (Cruciferae) roots on growth of vesicular-arbuscular mycorrhizal fungi. New Phytol. 110:217-225.

Graham, J. H. 1982. Effect of citrus exudates on germination of chlamydospores of the vesicular-arbuscular mycorrhizal fungus Glomus epigaeum. Mycologia 74:831-835.

Hirsch, A. M., and Kapulnik, Y. 1998. Signal transduction pathways in mycorrhizal associations: Comparisons with the Rhizobium-legume symbiosis. Fungal Genet. Biol. 23:205-212.

Koide, R. T., and Schreiner, R. P. 1992. Regulation of the vesiculararbuscular mycorrhizal symbiosis. Annu. Rev. Plant Physiol. Plant Mol. Biol. 43:557-581.

Long, S. R. 1989. Rhizobium-legume nodulation: Life together in the underground. Cell 56:203-214.
Mosse, B., and Hepper, C. 1975. Vesicular-arbuscular mycorrhizal infections in root organ cultures. Physiol. Plant Pathol. 5:215-223.

Nagahashi, G., and Douds, D. D. 1999. A rapid and sensitive bioassay with practical application for studies on interactions between root exudates and arbuscular mycorrhizal fungi. Biotechnol. Tech. 13:893897.

Nair, M. G., Safir, G. R., and Siqueira, J. O. 1991. Isolation and identification of vesicular-arbuscular mycorrhiza-stimulatory compounds from clover (Trifolium ripens) roots. Appl. Environ. Microbiol. 57: 434-439.

Paula, M. A., and Siqueira, J. O. 1990. Stimulation of hyphal growth of the VA mycorrhizal fungus Gigaspora margarita by suspensioncultured Pueraria phaseoloides cells and cell products. New Phytol. 115:69-75.

Poulin, M.-J., Simard, J., Catford, J.-G., Labrie, F., and Piché, Y. 1997. Response of symbiotic endomycorrhizal fungi to estrogens and antiestrogens. Mol. Plant-Microbe Interact. 10:481-487.

Powell, C. L. 1976. Development of mycorrhizal infection from endogone spores and infected root segments. Trans. Br. Mycol. Soc. 66: 438-445.

Regvar, M., Gogala, N., and Zalar, P. 1996. Effects of jasmonic acid on mycorrhizal Allium sativum. New Phytol. 134:703-707.

Rhodes, M. J. C., 1994. Physiological roles for secondary metabolites in plants: some progress, many outstanding problems. Plant Mol. Biol. 24:1-20.

St.-Arnaud, M., Hamel, C., Caron, M., and Fortin, J. A. 1995. Endomycorhizes VA et sensibilité des plantes aux maladies: Synthèse de la littérature et mécanismes d'interaction potentiels. Pages 51-87 in: La symbiose mycorhizienne. Etat des connaissances. Orbis Publishing, Frelighsburg, Canada.

Shirley, B. W. 1996. Flavonoid biosynthesis: "New" functions for an "old" pathway. Trends Plant Sci. 1:377-382.

Smith S. E., and Read, D. J. 1997. Mycorrhizal symbiosis. 2nd ed. Academic Press, San Diego, CA.

Tawaraya, K., Watanabe, S., Yoshida, E., and Wagatsuma, T. 1996. Effect of onion (Allium cepa) root exudates on the hyphal growth of $\mathrm{Gi}$ gaspora margarita. Mycorrhiza 6:57-59.

Tsai, S. M., and Phillips, D. A. 1991. Flavonoids released naturally from alfalfa promote development of symbiotic Glomus spores in vitro. Appl. Environ. Microbiol. 57:1485-1488.

Vierheilig, H., Bago, B., Albrecht, C., Poulin, M.-J., and Piché, Y. 1998. Flavonoids and arbuscular-mycorrhizal fungi. Pages 9-33 in: Flavonoids in the Living System. B. Buslig and J. Manthey, eds. Plenum Press, New York.

Vierheilig, H., and Piché, Y. 1995. Facteurs biochimiques potentiellement impliqués dans les interactions entre les champignons endomycorhiziens et leurs plantes non-hotes. Pages 109-123 in: La symbiose mycorhizienne. Etat des connaissances. Orbis Publishing, Frelighsburg, Canada.

Widholm, J. A. 1977. Relation between auxin autotrophy and tryptophan accumulation in cultured plant cells. Planta 134:103-108.

Xie, Z.-P., Starhelin, C., Vierheilig, H., Wiemken, A., Jabbouri, S., Broughton, W. J., Vögeli-Lange, R., and Boller, T. 1995. Rhizobial nodulation factors stimulate mycorrhizal colonization of nodulating and nonnodulating soybeans. Plant Physiol. 108:1519-1525.

Yokota, T. 1997. The structure, biosynthesis and function of brassinosteroids. Trends Plant Sci. 2:137-143. 